\title{
A Study on the Effects of Material to Liquor Ratio on the Colorfastness of Synolon Yellow EXW Fluorescent Disperse Dye
}

\author{
Azizul Islam ${ }^{1}, \operatorname{Rashaduzzaman}^{1}$, Mahbubur Rahman $^{1}$, Jagannath Biswas ${ }^{1}$, Elias Khalil ${ }^{2}$ \\ ${ }^{1}$ Department of Textile Engineering, Green University of Bangladesh, Dhaka, Bangladesh \\ ${ }^{2}$ Textile Engineering Department, World University of Bangladesh, Dhaka, Bangladesh
}

Email address:

azizul.tex@green.edu.bd (A. Islam), mithun.tex@green.edu.bd (Rashaduzzaman),mahbub.tex@green.edu.bd (M. Rahman), jbiswas.tex@green.edu.bd (J. Biswas),eliaskhali152@gmail.com (E. Khalil)

\section{To cite this article:}

Azizul Islam, Rashaduzzaman, Mahbubur Rahman, Jagannath Biswas, Elias Khalil. A Study on the Effects of Material to Liquor Ratio on the Colorfastness of Synolon Yellow EXW Fluorescent Disperse Dye. International Journal of Materials Science and Applications.

Vol. 5, No. 6, 2016, pp. 248-253. doi: 10.11648/j.ijmsa.20160506.13

Received: September 11, 2016; Accepted: September 21, 2016; Published: October 20, 2016

\begin{abstract}
This study highlighted the influence of change in material to liquor ratio on the colorfastness properties of Synolon Yellow EXW fluorescent disperse dye applied on knitted polyester fabric in exhaust dyeing method. Three different liquor ratios $(1: 6,1: 8$ and $1: 10)$ were used and dye shade percentages were $0.5 \%, 1.0 \%$ and $1.5 \%$. The results showed that an increment in liquor ratios increased the colorfastness to washing (color change) for the shade percentages of 0.5 and 1.5 . Wash fastness (color staining) grading was not satisfactory when material to liquor ratio is 1:6. Increasing the amount of liquor resulted least color bleeding. No color fading has been observed in dry rubbing test for 1:10 material to liquor ratio. Increment in the material to liquor ratios resulted better dry and wet rubbing fastness for both color change and color staining. Variation in the liquor ratios showed no effects on the abrasion resistance property.
\end{abstract}

Keywords: Fluoroscent Disperse Dye, Solubility, Liquor Ratio, Abrasion Resistance, Fluorescent Dye, Rubbing Fastness, Wash Fastness

\section{Introduction}

Disperse dye of hydrophobic nature has extremely poor solubility in water (Trotman, 1984) [1]; for this reason dispersing agent is added to the dye bath to maintain dispersion stability, especially in the case of high temperature dyeing (Bukinshaw, 1995) [2]. In dye bath, the dye transfer to fiber from the micelles aggregate of surfactant molecules dispersed in a liquid colloid. As micelles empty their dye, they reform and dissolve more dye from the solid particles [3]. In presence of dispersing agents, the following equilibrium situation is set up (fig 1) [4]. Satisfactory fastness to light, washing, rubbing, sublimation and burnt gas fumes, is particularly significant for disperse dyes [5]. The dyeing of artificially made fibres with disperse dyes generally have good fastness properties [6]. After the applications of fluorescent azo disperse dyes on polyester fiber, it has been found that it enhances various fastness properties [7]. Experiment showed the increase of photo physical properties after application of fluorescent acid azo dyes on wool, silk and nylon [8]. Fluorescent disperse dyes have the unique property of absorbing in the UV range and emitting in the visible region of the electromagnetic spectrum and which owe their potential application to their intense fluorescence properties [9]. The application of fluorescent dyes are associated with their ability to attract attention, because of the remarkable vivid brilliance of the color and dyes are associated with their ability to attract attention, because of the remarkable vivid brilliance of the colors [10] Synolon EXW dyes are state-of-the-art disperse dyes with the highest wash fastness. They meet the requirements of the major retailers and even the most severe fastness tests [11]. They are highly recommended for Polyester/Elastin blends, especially for sportswear [12]. At $120^{\circ} \mathrm{C}$ temperature the dye exhaustion of Synolon Yellow EXW fluorescent disperse dye was found $30 \%$ and this increased to $60 \%$ when the temperature raised to $130^{\circ} \mathrm{C}$. After 
40 minutes of run time the exhaustion $\%$ increased to $70 \%$ [13].

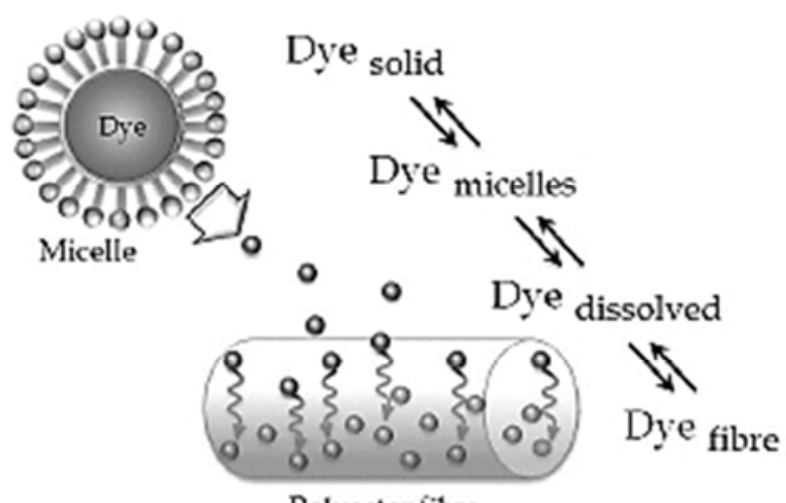

Polyester fibre

Fig. 1. Dyeing mechanism of Disperse Dye.<smiles>Nc1ccc(O)c2c1C(=O)c1c(N)ccc(Br)c1C2=O</smiles>

Fig. 2. Chemical structures of Synolon EXW fluorescent dye.

Fluorescent dyes can be applied in various differentiated fields. But one of the leading application fields where fluorescent dyes have long been used is for the dyeing of flat materials, especially textiles. The application of fluorescent dyes results a significant increase in color brightness, which makes the dyed materials more easily perceptible. The materials dyed with fluorescent dyes render a unique advantage for manufacturing sports clothing and clothing for special services, such as fire brigades and the police because of the intensified perceptibility [14]. Recently, the application of fluorescent dyes in medical diagnostic and biochemical investigations has developed extremely dynamically [15].In comparison of disperse dyes of different auxiliary groups, dyes containing benzothiazolyl residue have better fastness properties than that of the azo disperse dyes based on 2-naphthol [16].

This paper mainly focuses on the study of colorfastness property to washing; rubbing and abrasion for Synolon Yellow EXW fluorescent disperse dye on knitted polyester fabric. The impact of change in material to liquor ratio on fastness property of this dye is highlighted in this study.

\section{Materials and Methods}

Scoured and bleached, optical brightener free 100\% polyester knitted fabric with GSM 110 was used for high temperature exhaust dyeing. Commercial fluorescent dye Synolon Yellow EXW sourcing from Kyung-In Synthetic Corporation was used in the experimental work. The chemicals and auxiliaries used such as dispersing agent, leveling agent, acetic acid and sequestering agent were of commercial grade. Dyeing was carried out on Lab Dyer 212 machine made by the company of MAG Solvics Private Limited, India. Colorfastness to washing (color change and color staining) of dyed samples at different material to liquor ratio was tested in MAG Wash Fastness Tester in ISO 105 CO6-C2S test method. Colorfastness to rubbing (dry and wet) was measured by ISO 105 X12 test method. Fabric abrasion resistance test was carried out in AbraSmart Abrasion Cum Pilling Tester (Martidale type) made by MAG Solvics Private Limited, India. ASTM D4966-98(2004) test method (Martindale abrasion test method) was followed to determine the abrasion resistance [17]. AATCC recommended grey scale was used for determining color change and staining.

\section{Experimental}

Polyester fabric was dyed with Synolon Yellow EXW fluorescent disperse dye at variable material to liquor ratios $(1: 6,1: 8,1: 10$ and $1: 15)$. Dye shade percentages were $0.5 \%$, $1 \%$ and $1.5 \%$. Each sample weight was 10 gram. 12 samples were dyed in respect of four different liquor ratios. Recipes of dyeing polyester fabric with Synolon Yellow EXW fluorescent disperse dye $(0.5 \%, 1 \%$ and $1.5 \%$ shade $)$ at four different liquor ratios are given in the table 1 .

Table 1. Recipes of dyeing polyester fabric with synolon yellow exw fluorescent disperse dye.

\begin{tabular}{lllll}
\hline Chemicals & Recipe: $\mathbf{1}$ & Recipe: 2 & Recipe: $\mathbf{3}$ & Recipe: $\mathbf{4}$ \\
\hline Dispersing Agent $(\mathrm{g} / \mathrm{l})$ & 1 & 1 & 1 & 1 \\
Acetic Acid $(\mathrm{g} / \mathrm{l})$ & 0.5 & 0.5 & 0.5 & 0.5 \\
Sequestering Agent $(\mathrm{g} / \mathrm{l})$ & 1 & 1 & 1 & 1 \\
Leveling Agent $(\mathrm{g} / \mathrm{l})$ & 1 & 1 & 1 & 1 \\
Temperature $(\mathrm{C})$ & $130^{\circ}$ & $130^{\circ}$ & $130^{\circ}$ & $130^{\circ}$ \\
Time (Minute) & 45 & 45 & 45 & 45 \\
$\mathrm{P}^{\mathrm{H}}$ & $4-5$ & $4-5$ & $4-5$ & $4-5$ \\
Liquor ratio & $1: 6$ & $1: 8$ & $1: 10$ & $1: 15$ \\
\hline
\end{tabular}

Procedure of dyeing polyester fabric with Synolon Yellow EXW fluorescent disperse dye $2 \%$ stock solution of dye, dispersing agent, acetic acid, sequestering agent and leveling agent were prepared. Dye bath was set at room temperature.
Chemicals and auxiliaries along with polyester fabric were poured into the dye bath. Temperature was raised to $60^{\circ} \mathrm{C}$ and ran for 10 minutes. Synolon Yellow EXW fluorescent dye was added in the dye bath and temperature was raised to $130^{\circ} \mathrm{C}$ at a 
gradient of $2^{\circ} \mathrm{C} /$ minute. Then dyeing was carried out for 45 minutes. Temperature was lowered to $80^{\circ} \mathrm{C}$. Hot rinse was carried out for 10 minutes and cold rinse was carried out at $40^{\circ} \mathrm{C}$. It is required to note that reduction clearing at temperature $80^{\circ} \mathrm{C}$ was avoided.

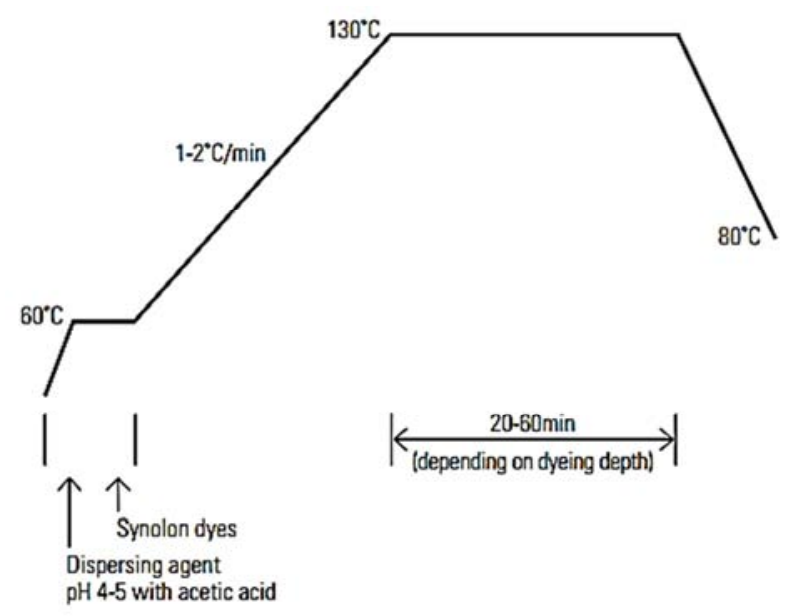

Fig. 3. Dyeing curve of Synolon Yellow EXW fluorescent disperse dye.

\section{Results and Discussions}

Color Fastness to Washing

The resistance of the loss of the color of any dyed or printed material in washing is referred to as its wash fastness. MAG wash fastness tester was used to wash the dyed samples. ISO recommended multifibre fabric was attached to the samples during washing. Color fastness to washing (color change and color staining) of dyed samples were determined according to the test method ISO $105 \mathrm{CO}-\mathrm{C} 2 \mathrm{~S}\left(60^{\circ} \mathrm{C}^{*} 30 \mathrm{~min}\right)$ [18].

Table 2. Ratings of colorfastness to washing.

\begin{tabular}{lll}
\hline Sl. No. & Grade & Meaning \\
\hline 01 & 1 & Very poor \\
02 & $1 / 2$ & Poor \\
03 & 2 & Fair \\
04 & $2 / 3$ & Slightly Fair \\
05 & 3 & Moderate \\
06 & $3 / 4$ & Good \\
07 & 4 & Very good \\
08 & $4 / 5$ & Excellent \\
Sl. No. & Grade & Meaning \\
09 & 5 & Outstanding \\
\hline
\end{tabular}

Wash fastness grading at variable material to liquor ratio is showed in table 3 . From the table 3 and figure 4 , it has been observed that, color fastness to washing (color change) rating is increasing if the material to liquor ratio is increased from 1 : 6 to $1: 10$ when the dye shade percentage is 0.5 . In terms of 1.0\% shade 1: 8 and 1: 10 liquor ratio shows excellent color change rating. Outstanding wash fastness is obtained at 1:8 and 1:10 liquor ratio when shade percentage is 1.5 . From the table 3 and figure 5, it has been found that, if the material to liquor ratio is $1: 6$, outstanding fastness in terms of color staining is obtained by $1.5 \%$ shade compared to $0.5 \%$ and $1.0 \%$ shade. Darker shade $(1.5 \%)$ provides comparatively better wash fastness with least color bleeding at three different liquor ratios.

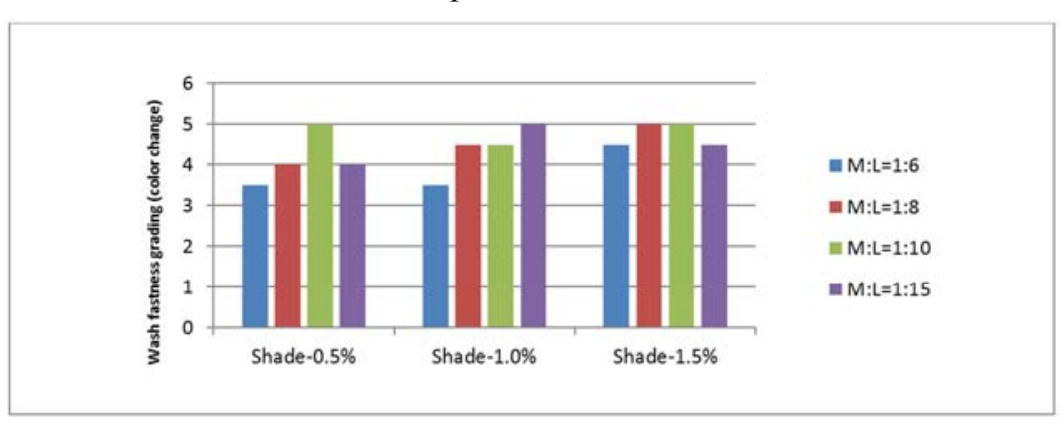

Fig. 4. Wash fastness ratings (color change) at variable liquor ratio.

Table 3. Wash fastness grading at variable liquor ratio.

\begin{tabular}{lllllll}
\hline Sample Details & & & & \\
Sample No. & $\begin{array}{l}\text { Dye\&shade\% } \\
\text { Synolon Yellow EXW }\end{array}$ & Liquor ratio & Color change grading & Remarks & Color staining grading & Remarks \\
\hline 1 & & $1: 6$ & $3 / 4$ & Good & 3 & Moderate \\
2 & $0.5 \%$ & $1: 8$ & 4 & Very good & $4 / 5$ & Excellent \\
3 & & $1: 10$ & 5 & Outstanding & 5 & Outstanding \\
4 & & $1: 15$ & 4 & Very good & 3 & Moderate \\
5 & $1 \%$ & $1: 6$ & $3 / 4$ & Good & 2 & Fair \\
6 & & $1: 10$ & $4 / 5$ & Excellent & $3 / 4$ & Good \\
7 & & $1: 15$ & 5 & Excellent & 4 & Very good \\
8 & $1: 6$ & $4 / 5$ & Outstanding & $4 / 5$ & Excellent \\
9 & $1.5 \%$ & $1: 8$ & 5 & Excellent & 5 & Outstanding \\
10 & & $1: 10$ & 5 & Outstanding & 5 & Outstanding \\
11 & & $4 / 5$ & Outstanding & $4 / 5$ & Excellent \\
12 & & & Excellent & 5 & Outstanding \\
\hline
\end{tabular}




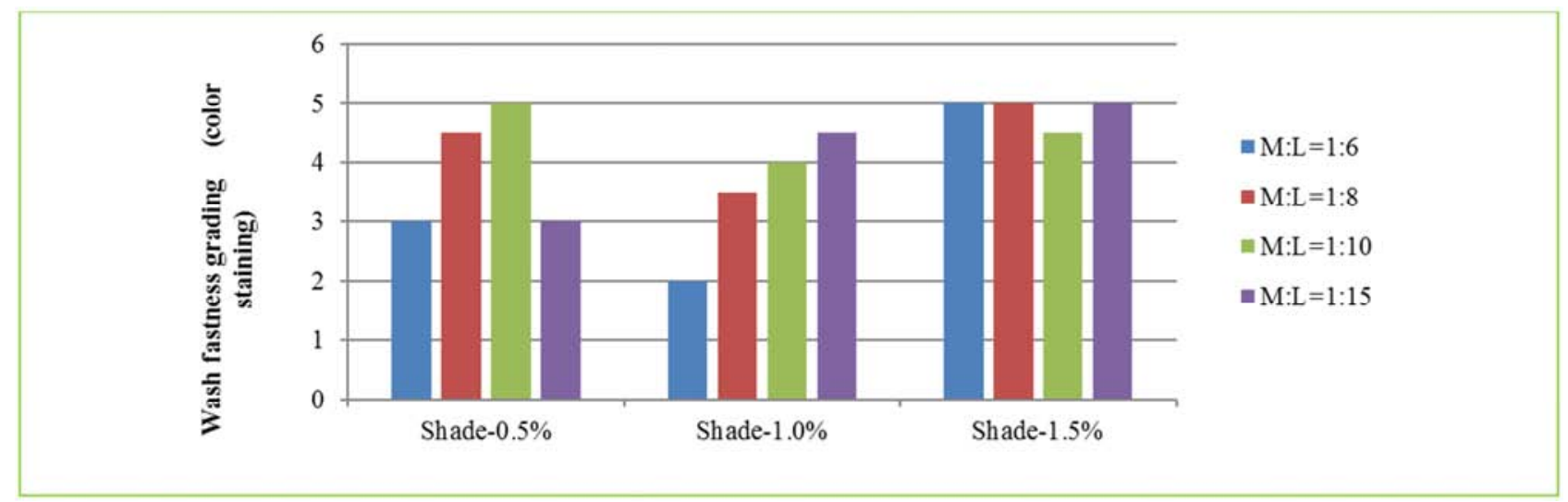

Fig. 5. Wash fastness ratings (color staining) at variable liquor ratio.

Color fastness to rubbing

Both dry and wet rubbing fastness of dyed samples was tested according to ISO 105 X12 test method [19]. ISO recommended crocking cloth was used to rub the specimen. The test specimen is rubbed to and fro (10 x $10 \mathrm{rub}, 1 \mathrm{rub} / \mathrm{sec}) \mathrm{by} \mathrm{means} \mathrm{of} \mathrm{crock}$ meter.

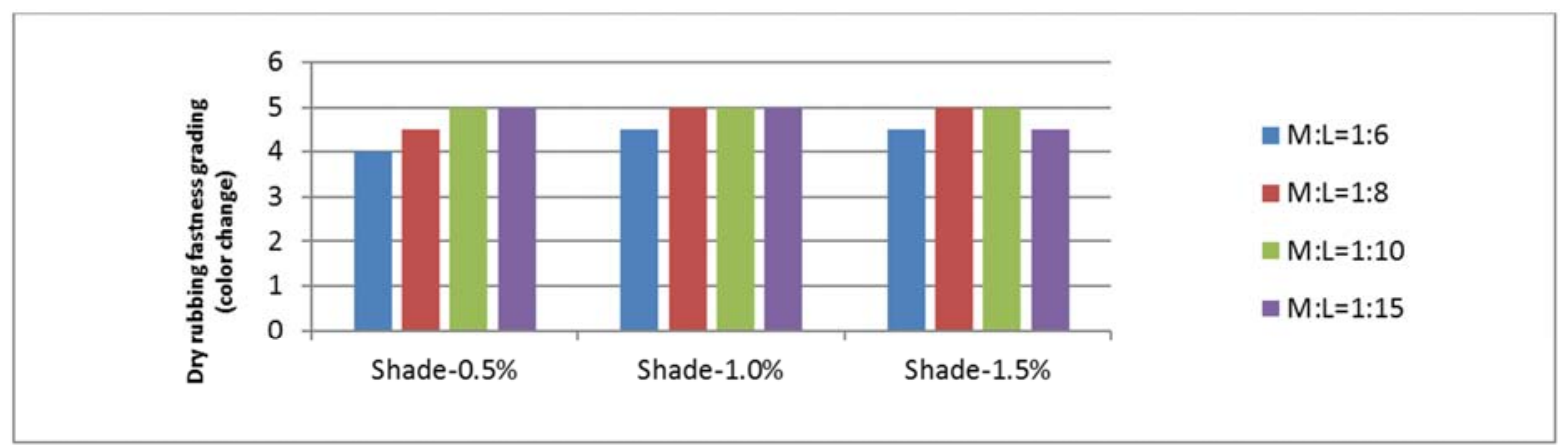

Fig. 6. Dry rubbing fastness ratings for color change at variable liquor ratio.

Table 4. Test results of dry and wet rubbing fastness.

\begin{tabular}{|c|c|c|c|c|c|c|}
\hline \multicolumn{3}{|c|}{ Sample Details } & \multicolumn{2}{|c|}{ Dry Rubbing Grade } & \multicolumn{2}{|c|}{ Wet Rubbing Grade } \\
\hline $\begin{array}{l}\text { Sample } \\
\text { No. }\end{array}$ & $\begin{array}{l}\text { Dye \& Shade\% } \\
\text { Synolon Yellow EXW }\end{array}$ & Used liquor ratio & Color change & Color staining & Color change & Color staining \\
\hline 1 & \multirow{3}{*}{$0.5 \%$} & $1: 6$ & 4 & 4 & 4 & $4 / 5$ \\
\hline 3 & & $1: 10$ & 5 & 5 & 5 & $4 / 5$ \\
\hline 4 & & $1: 15$ & 5 & 5 & $4 / 5$ & $4 / 5$ \\
\hline 5 & \multirow{3}{*}{$1 \%$} & $1: 6$ & $4 / 5$ & 5 & $4 / 5$ & 4 \\
\hline 7 & & $1: 10$ & 5 & 5 & 5 & 5 \\
\hline 8 & & $1: 15$ & 5 & $4 / 5$ & $4 / 5$ & 4 \\
\hline 9 & \multirow{4}{*}{$1.5 \%$} & $1: 6$ & $4 / 5$ & 4 & 4 & $3 / 4$ \\
\hline 10 & & $1: 8$ & 5 & $4 / 5$ & $4 / 5$ & $4 / 5$ \\
\hline 11 & & $1: 10$ & 5 & 5 & 5 & $4 / 5$ \\
\hline 12 & & $1: 15$ & $4 / 5$ & $4 / 5$ & 4 & 4 \\
\hline
\end{tabular}

finger. For wet rubbing test, crocking cloth was wetted with distilled water and to keep 100\% pick up, excess water was removed by blotting paper.

Figure 6 shows outstanding dry rubbing fastness rating without any color fading is achieved for three shades at M: L @ 1:10 Dry rubbing fastness for color change is increasing with the increase of material to liquor ratio from 1:6 to 1:10.For material to liquor rato @ 1:8, both shade 1\% and 1.5\% shows outstanding dry rubbing fastness rating.

In terms of color staining, Synolon Yellow EXW shows no color bleeding when material to liquor ratio is 1:10.Less material to liquor ratio, more color bleeding and vice versa.

From figure 8, it has been observed that, color fastness to wet rubbing (color change) is outstanding when the material to liquor ratio is $1: 10$ at every shade percentage. Wet rubbing fastness grading (color change ) is also excellent for material to liquor ratio (a) 1:8 and comparatively least performance in wet fastness grading is obtained while M:L @ 1:6 is used. 


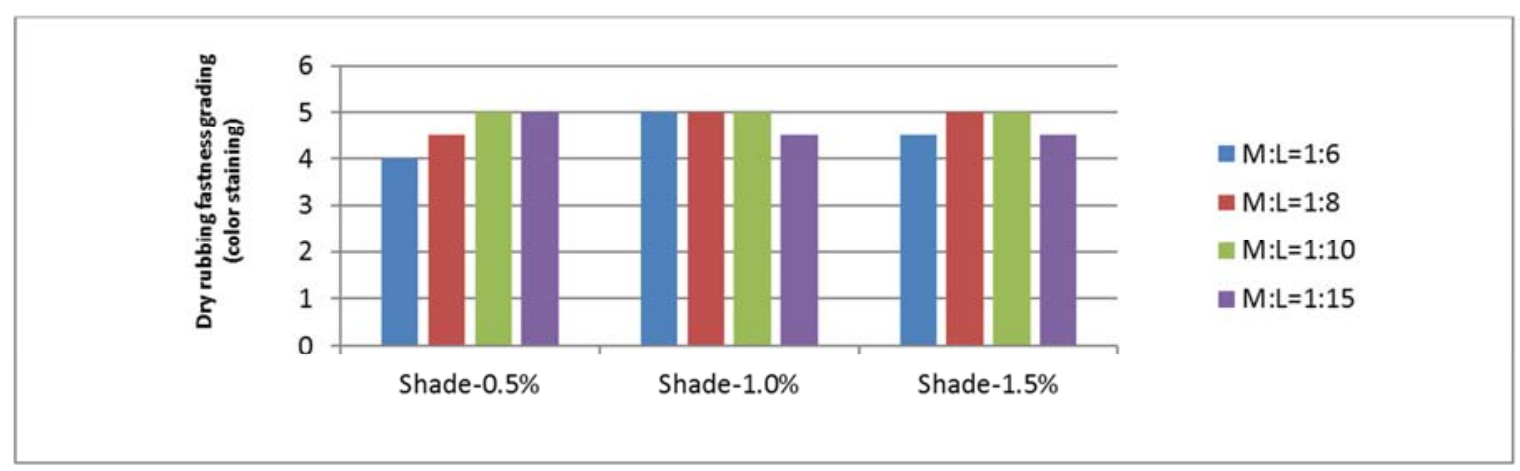

Fig. 7. Dry rubbing fastness grading (color staining) at variable liquor ratio.

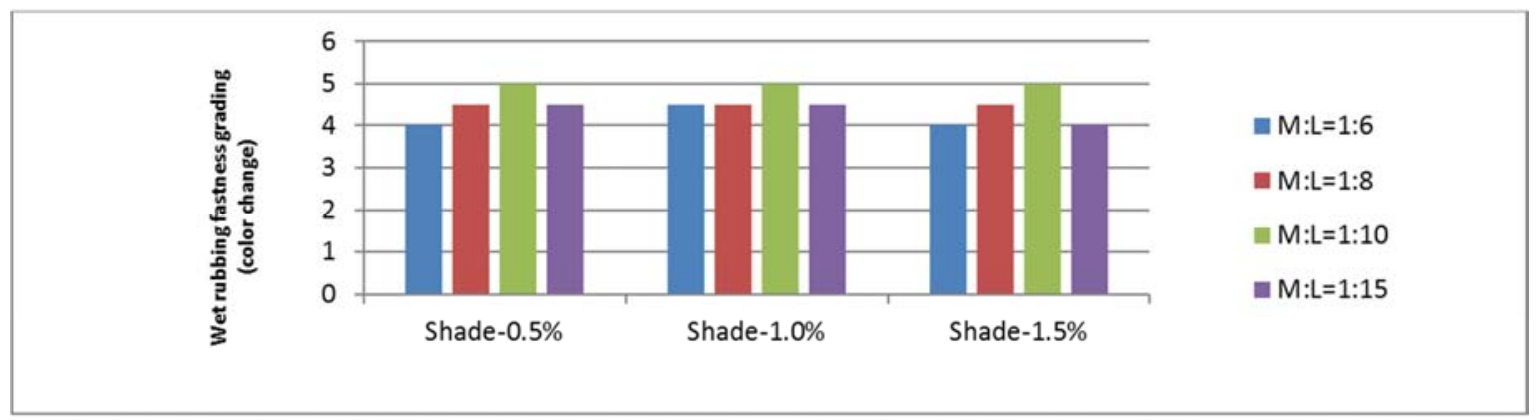

Fig. 8. Wet rubbing fastness ratings for color change at variable liquor ratio.

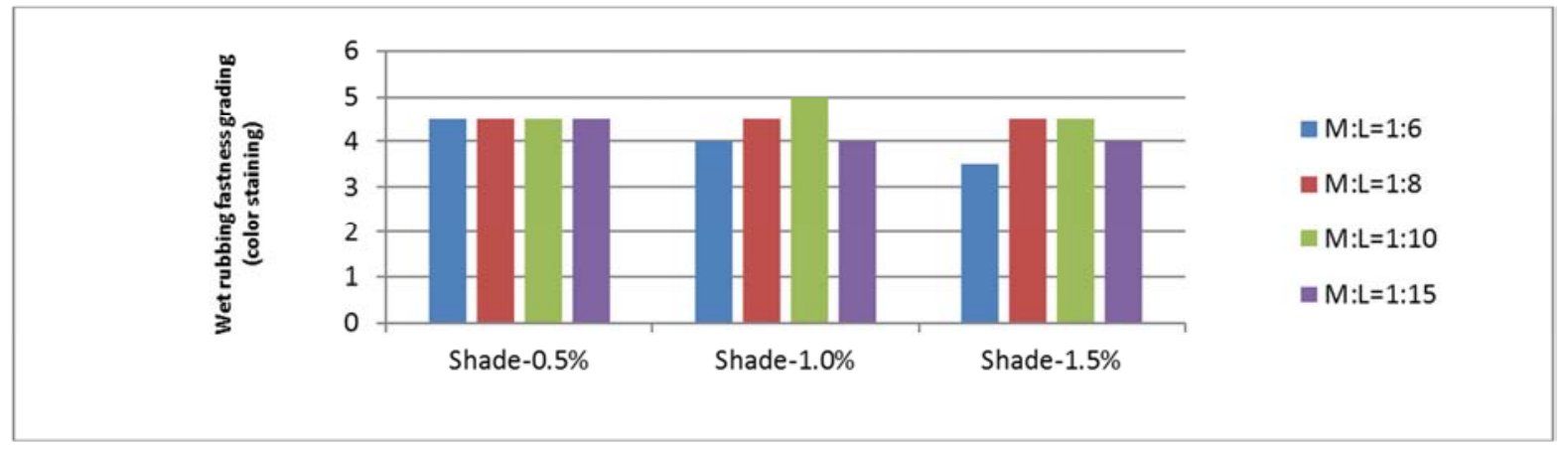

Fig. 9. Wet rubbing fastness ratings for color staining at variable liquor ratio

In terms of wet rubbing test, the least color staining rate has been found when the dispersing agent concentration was $2.0 \mathrm{~g} / 1$ (Fig. 9). The wet rubbing fastness has been decreased with the increase of shade percentage. It also has been observed that the wet rubbing fastness in terms of color bleeding is increased with the increase of dispersing agent concentrations. $0.5 \%$ shade of Synolon Yellow EXW fluorescent disperse dye exhibited the best performance of wet rubbing fastness compared to $1.0 \%$ and $1.5 \%$ shade.

Table 5. Test results of fabric abrasion resistance.

\begin{tabular}{llllll}
\hline Sample Details & & & \multirow{2}{*}{ Grey scale rating } & \multirow{2}{*}{ Remarks } \\
\cline { 1 - 3 } Sample No. & Dye \& Shade\% (Synolon Yellow EXW) & Used Dispersing agent(gm/l) & Excellent \\
\hline 1 & & 0.5 & 5 & Excellent \\
2 & $0.5 \%$ & 1 & 5 & Excellent \\
3 & & 1.5 & 5 & Excellent \\
4 & & 2 & 5 & Excellent \\
5 & $1 \%$ & 1 & 5 & Excellent \\
6 & & 1.5 & 5 & Excellent \\
7 & & 2 & 5 & Excellent \\
8 & $1.5 \%$ & 0.5 & 5 & Excellent \\
9 & & 1 & 5 & 5 & Excellent \\
10 & & 1.5 & 5 & Excellent \\
11 & & 2 & 5 & Excellent \\
12 & & 5 & \\
\hline
\end{tabular}


According to ASTM (American society for Testing \& Materials), the abrasion resistance of a fabric is defined as the resistance of a fabric to abrasion, usually stated in terms of a number of abrasion cycles. Abrasion resistance is the ability of a fabric to resist surface wear caused by flat rubbing contact with another material. In this study, the Martindale abrasion test method has been implied. Samples were tested up to 5000 abrasion cycles and checked in each 1000 cycle interval. 9 $\mathrm{KPa}$ pressure was applied during each test. AATCC recommended grey scale has been used to determine the degree of changes in shades.

The test results showed excellent abrasion resistance (Table 5). No fading or shade change of Synolon Yellow EXW fluorescent disperse dye was occurred after 5000 abrasion cycles. No holes were produced and no threads were broken. The variation in the concentration of dispersing agent has no considerable effects on the abrasion resistance property.

\section{Conclusion}

The Synolon Yellow EXW fluorescent disperse dye shows no change to repeated washing and rubbing. The average colorfastness to washing and rubbing is excellent. No color fading has been found after 4000 abrasion cycles and showed excellent performance. This dye is distinctly recommended for sportswear. We could not carry out the light fastness test because of the unavailability of testing machine. But research journal revealed the outstanding light fastness property of Synolon Yellow EXW fluorescentdye. Further research is required to dye polyester fibre with this dyestuff at lower temperature.

\section{Acknowledgment}

We would like to express our gratitude to Green University of Bangladesh for providing us the lab facilities to conduct the required tests successfully.

\section{References}

[1] Trotman. E. R. (1984), Dyeing and Chemical Technology of Textile Fibres, John Wiley \& Son, ISBN 0-471-80910-1, New York, USA.

[2] Burkinshsaw, S. M (1995).Chemical Principles of Synthetic Fibre Dyeing, Blackie Academic \& Professional, ISBN 0-7514-0043-2, Glasgow. UK.

[3] Ingamells, W. (1993), Colour for Textiles: A User's Handbook, SDC, ISBN 0-901-95648-1, Bradford, UK.
[4] Johnson, A. (1989). The theory of coloration of textiles, SDC, ISBN 0-901-95648-1, Bradford, UK.

[5] Dawson, J. F. (1984). Fifty Years of Disperse DyeRev. Prog. Coloration, Vol. 14, No. 1, (June 1984), pp 90-97, ISBN 0557-9325.

[6] Broadbent, A. D. (2001). Basic Principles of Textile Coloration, SDC, ISBN 0-901956-76-7, Bradford, UK.

[7] M. A. Satam, R. K. Raut and N.Sekar, "Fluorescent Azo Disperse Dyes from 3 - (1,3-Benzothaizol-2-yl) Naphtha-len-2-ol and Comparision with 2-Naphthol Analogs," Dyes and Pigments, Vol. 96' No1, 2013, pp. 92103, http://dx.doi.org/10.1016/j.dyepig.2012.07.019.

[8] M. A. Satam, R. K. Raut and N. Sekar, "Fluorescent AzoDisperse Dyes from 3-(1, 3-Benzothiazol-2-yl) Naphtha-len-2-Ol and Comparison with 2-Naphthol Analogs," Dyes and Pigments, Vol. 97, No. 1, 2013, pp. 32-42, http://dx.doi.org/10.1016/j.dyepig.2012.11.007.

[9] R. M. Christie, "Fluorescent Dyes", Review of progress in coloration, 1993, vol 23, pp: 1-18.

[10] Higgins SD, Towns A D, "Standing out in a crowd: Fluorescence and fluorescent dyes", ChimicaOggi (Chemistry Today).

[11] http://www.kisco.co/wp-content/uploads/2015/09/Synolon-EX W-flyer. pdf.

[12] KISCO Disperse Dyes, Kyung-In Synthetic Corporation, Yeomchang-Dong Kangseo-Gu, Seoul, 157-040, Korea, 2010, http://www.kyungin.co.kr.

[13] Eun-mi Kim, Yong-hwan Noh, Gwang-ung Yang and Jae-hong Choi, "A Study on Dyeing Properties of Self Moisture Control Knitted Fabric", Textile Coloration and Finishing, Vol. 26, No. 2, June 14, 2014, http://dx.doi.org/10.5764/TCF.2014.26.2.79.

[14] Szuster, L., Kaźmierska, M. and Król, I., 2004. Fluorescent dyes destined for dyeing high-visibility polyester textile products. Fibres \& Textiles in Eastern Europe, (1 (45)), pp. 70-75.

[15] Satam, M. A., Raut, R. K. and Sekar, N., 2013. Fluorescent azo disperse dyes from 3-(1, 3-benzothiazol-2-yl) naphthalen-2-ol and comparison with 2-naphthol analogs. Dyes and pigments, 96 (1), pp. 92-103.

[16] ASTM D4966-98 (2004), Standard Test Method for Abrasion Resistence of Textile Fabrics (Martindale Abrasion Tester Method), ASTM International, West Conshohocken, PA, 2004, www. Astm.

[17] ISO 105-C06, Textiles---Tests for coloru fastness- Part C06: Coolor fastness to domestic and commercial laundering, http://www.iso.org/iso/catalogue_detal..htm?csnumber=51276.

[18] ISO 105-X12: 2001, Textiles-Tests for colour fastness- PartX12: www.iso.org/iso/catalogue_detail.htm?csnumber $=32339$. 